\title{
Analytical Microsystem for the Monitoring and Analysis of Cobalt in Aqueous Solutions Using LTCC Technology
}

Olga Natalia Bustos López, ${ }^{1 *}$ Francisco Valdés Perezgasga, ${ }^{1}$ Héctor Aurelio Moreno Casillas, ${ }^{1}$ Julián Alonso Chamarro, ${ }^{2}$ and Hesner Coto Fuentes ${ }^{1}$

1 Instituto Tecnológico de La Laguna, México. Cuauhtémoc y Revolución s/n, 27000 Torreón, Coahuila, México. bustosolga@yahoo.com.mx

2 Universidad Autónoma de Barcelona, Edificio C-Campus de la UAB, 08193 Bellaterra, Barcelona, España.

Received September 25th, 2013; Accepted June 10th, 2014

\begin{abstract}
This work is focused on the design and implementation of a microsystem for continuous colorimetric determination of cobalt in aqueous solutions in real time. The main goal is the colorimetric determination of cobalt by adapting colorimetric methodologies used in discontinuous analysis systems to a continuous flow system and its subsequent miniaturization using the LTCC (Low Temperature Cofired Ceramics) technology. The measure absorbance was recorded using an optical detection system based on a LED (Light Emitting Diode) with a wavelength of $540 \mathrm{~nm}$.

Keywords: Colorimetry; Continuous flow; LTCC; Laboratory Virtual instrumentation; LED.
\end{abstract}

\section{Introduction}

In the last decades there has been a growing interest in the measurement of low concentrations of analytes of industrial and environmental interest with increasing speed, precision and accuracy [1]. To comply with these requirements there is a need for methods and instruments that allow in-situ quantitative and qualitative analysis with high selectivity, some of those methods include Lab-on-a-chip systems and Micro Total Analysis Systems ( $\mu$ TAS), which have great advantages because they can combine versatility, integrity, miniaturization and automation[2,3].

Glass and silicon are the materials commonly employed in this kind of systems. However, LTCC technology, also called green ceramics, is a great alternative for the construction of micro analysis systems for in situ testing. It can provide reliable results in real time $[4,5]$. The LTCC technology is appropriate because allows the fabrication of robust, multilayer devices using the simplicity of machining in a "green state" [6]. The LTCC technology also accommodates an easy integration of microelectronic circuits that may be integrated in the micro analysis system, or in a separate ceramic board forming a hybrid configuration [7].

The present work aims at the development of a system for the detection of cobalt in continuous flow $[8,9]$. The analytical method uses 3-hydroxyl-4-nitroso-2, 7-naphthalenedisulfonic acid disodium salt known as Nitroso-R-salt $[10,11]$ or NRS, as the main reagent. Sulfonate groups in the NRS molecule make a complex with cobalt that is soluble in water but insoluble in non-polar solvents, making it useful in the spectrophotometric detection of cobalt in aqueous solutions. Reagent NRS, was
Resumen. El presente trabajo se basa en el diseño e implementación de un sistema para la determinación colorimétrica, continua y en tiempo real de cobalto en disoluciones acuosas. El objetivo principal de la investigación es la detección colorimétrica de Co mediante la adaptación de metodologías colorimétricas utilizadas en sistemas de análisis discontinuos a sistemas de flujo continuo, y su posterior miniaturización mediante la tecnología LTCC (Low Temperature Cofired Ceramics). Las absorbancias obtenidas son registradas mediante un sistema de detección óptico basado en: un LED (Light Emmiting Diode) a $540 \mathrm{~nm}$.

Palabras clave: colorimetría, flujo continuo, LTCC, LabView, LED.

first introduced by van Klooster (1921) [12], in the determination of cobalt and was subsequently used by various investigators for determination of iron, copper and nickel, with favorable results [13-15].

In the electrolytic zinc process, specifically after leaching; cobalt, copper and some other elements are considered impurities and are still present in the solution. Usually its removal is carried out with the aid of zinc dust. The required amount of zinc powder depends on the amount of impurities contained in the solution $[16,17]$.

This work proposes an alternate procedure for the detection of cobalt adapting conventional colorimetric methods in continuous flow to reduce analysis time and cost at industrial level.

\section{Material and methods}

\section{Equipment}

For the manufacture of the LTCC device the following equipment was used: a CNC machine (Proto Mat ${ }^{\circledR}$ C100/HFLPKF, Garbsen, Germany). For the lamination of the machined ceramics a hydraulic uniaxial press was used (MAFSA, Torreon, Coahuila, México). This press has pressure plates that are heated to a temperature of $100^{\circ} \mathrm{C}$ and helps adhere the ceramic layers to one another before entering the CBFL518C box furnace (ColeParmer, Vernon Hills, Illinois EUA).

For the analytical part the following was used: a spectrophotometer (UV-3101PC, Shimadzu), a Jenway 6305 model UV/VIS spectrophotometer (Wilkens-Anderson Com- 
pany, Chicago, Illinois USA), to evaluate the results of the developed continuous flow system, a four channel peristaltic pump(MINIPULS® 3, F117606, GilsonInc, Middleton, WI, USA) and a six way valve (Modular Valve Positioners, RS232,Hamilton, Reno, NV U.S.A).

The optical detection system was based on a LED (Lumex SSL-LX100T123UPGC, Lumex Global Headquarters, Illinois USA) with a wavelength of $540 \mathrm{~nm}$, an optical fiber for transmission of the signal to the control and data acquisition board and a photodetector (630-HFBR-2526Z, Avago Technologies, San José, CA USA) integrating a photodiode and a transimpedance amplifier that converts current into voltage [18-20].

\section{Reagents and solutions}

All reagents used were analytical grade, (Sigma Aldrich) and solutions were prepared using double distilled water. The Co standards were prepared from a stock solution of $1000 \mathrm{mgl}^{-1}$ (Sigma Aldrich), the NRS reagent was prepared at a concentration of $2.6 \times 10^{-3} \mathrm{M}$, the buffer solution was prepared using 0.5 M Sodium Citrate and 2 M Sodium Acetate, and as the carrier a $0.25 \mathrm{M}$ Sulfuric acid solution was used. A solution composed of NRS, buffer and sulfuric acid was used as a blank for all tests.

\section{Procedure}

The methodology proposed by Hayashibe [21] was considered for the design of a robust and miniaturized device capable of measuring cobalt in aqueous solutions [22-25]. This methodology was modified and implemented in the micro fluidic system $[26,27]$ considering the number of reagents involved and their mixing order.

The manufacture of the device begins with the design of each layer and their assembling. The machined layers are aligned, thermo laminated using a press with hot plates at 100 ${ }^{\circ} \mathrm{C}$. The last step is the sintering of the layers in an oven using a temperature ramp of $20^{\circ} \mathrm{C}-350{ }^{\circ} \mathrm{C}-850^{\circ} \mathrm{C}$. Figure 1 shows the design of the ceramic, the optical path is of $2 \mathrm{~mm}$.

A peristaltic pump is used to introduce fluids to the LTCC microsystem. This pump feeds the buffer, the NRS and the dilu-
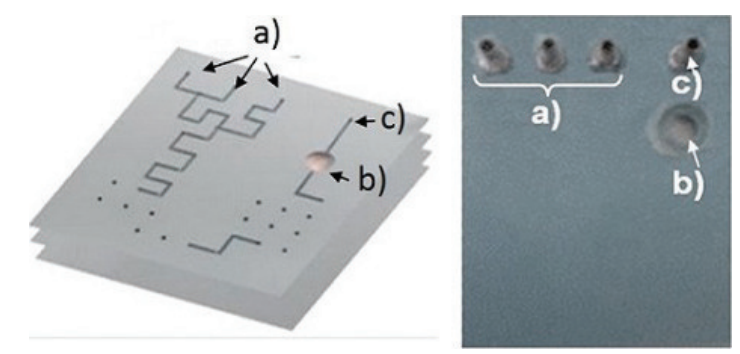

Fig. 1. Design of the LTCC platform. Dimensions are $5.6 \times 4.4 \times 2.5$ $\mathrm{mm}$ with a $2 \mathrm{~mm}$ optical path. End device, a) Inputs to the system, b) Optical detection window, c) System output. ent or carrier to the LTCC device. The sample fills up a loop, in order to measure the injection volume, which is subsequently introduced to the system through a six way valve, mixing it with the other solutions to allow the reaction to occur and therefore the ensuing detection of cobalt [28-30].

The signal generated by the photodetector is processed by an analog circuit to condition it for the input signal of the data acquisition board (PCI6221, National Instruments). The acquired signal is then processed by LabVIEW for its storage, processing, and display on a personal computer. Figure 2 shows a schematic diagram of the system; Figure 3 shows the different components used in the microsystem: a) peristaltic pump and six-way valve, b) assemble of the components of the optical detection system to the detection window of the analyzer LTCC and c) the electronic system manufactured

Although the best absorbance for cobalt detection is about $420 \mathrm{~nm}$, Hayashibe et al. use a wavelength of $520 \mathrm{~nm}$ for analysis of cobalt, and in this study a $540 \mathrm{~nm}$ wavelength is used because it is the one used in Met Mex Peñoles electrolytic zinc plant.

Flow rate and sample injection volume were selected where the largest absorbance for the measured cobalt concentrations were attained.

Once that these conditions and parameters were set, a series of samples were run in the LTCC micro system to evaluate the absorbance detected for each cobalt concentration. Measurements were made randomly and triplicated.

Finally, measurements were done with the same cobalt solutions at different moments in a period of 13 days to test the reproducibility and the repeatability of the system. Again, all measurements were made randomly and triplicated.

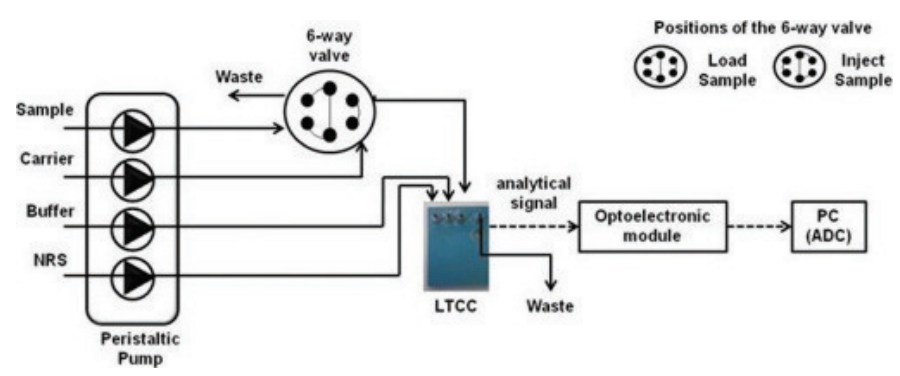

Fig. 2. Schematic diagram of the system used.
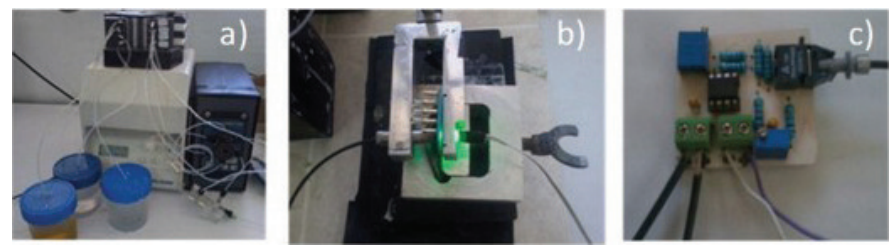

Fig. 3. a) Peristaltic pump and injection valve, b) Elements of detection system optical device adapted to LTCC, c) The electronic system used. 


\section{Results and discussion}

Figure 4 shows the absorption spectra of the different cobalt concentrations, in the range of 400 to $600 \mathrm{~nm}$. Although a greater absorbance was detected near $420 \mathrm{~nm}$, a wavelength of $540 \mathrm{~nm}$ was chosen, because the calibration curves of concentration vs. absorbance show similar sensitivity and a correlation $\left(\mathrm{R}^{2}\right)$ very close to unity at $540 \mathrm{~nm}$.

Figure 5, shows the results of the second test regarding the response of the system to different flow rates and sample volumes.

According to Figure 5, the better response of the system is achieved with a flow rate of $500 \mu \mathrm{L} / \mathrm{min}$ and sample volume of $250 \mu \mathrm{L}$. Therefore, these were chosen as the hydrodynamic parameters of the system for the following tests.

In Figure 6, the results of the LTCC micro system response for a run of seven cobalt concentrations are shown.

Figure 7 shows the linear equation of the absorbance vs. concentration response and its correlation coefficient is presented. Measurements were made at $540 \mathrm{~nm}$, with a flow rate of $500 \mu \mathrm{L} / \mathrm{min}$ and a sample volume of $250 \mu \mathrm{L}$.

Table 1 presents absorbance vs. concentration obtained at different days for a 13-day period, to assess the reproducibility of the results.

Results from Table 1 were used to build a single calibration curve that is presented in Figure 8 along with its linear equation and correlation coefficient.

The repeatability of the micro system is calculated as the relative standard deviation (\% RSD) to a data series by selecting at random the concentration of $3 \mathrm{mg} / \mathrm{L}$ resulting in a value of $4.28 \%$ ( $n=13,98 \%$ confidence), the limit of detection (LOD) is $0.0169 \mathrm{mg} / \mathrm{L}$, the limit of quantification (LOQ) is $0.051 \mathrm{mg} / \mathrm{L}$, and the molar absorption coefficient $\varepsilon$ corresponds to $2.748 \times 10^{3} \mathrm{M}^{-1} \mathrm{~cm}^{-1}$.

Table 2 shows a comparison of parameters operating the system proposed by Hayashibe et al., and the system implemented.

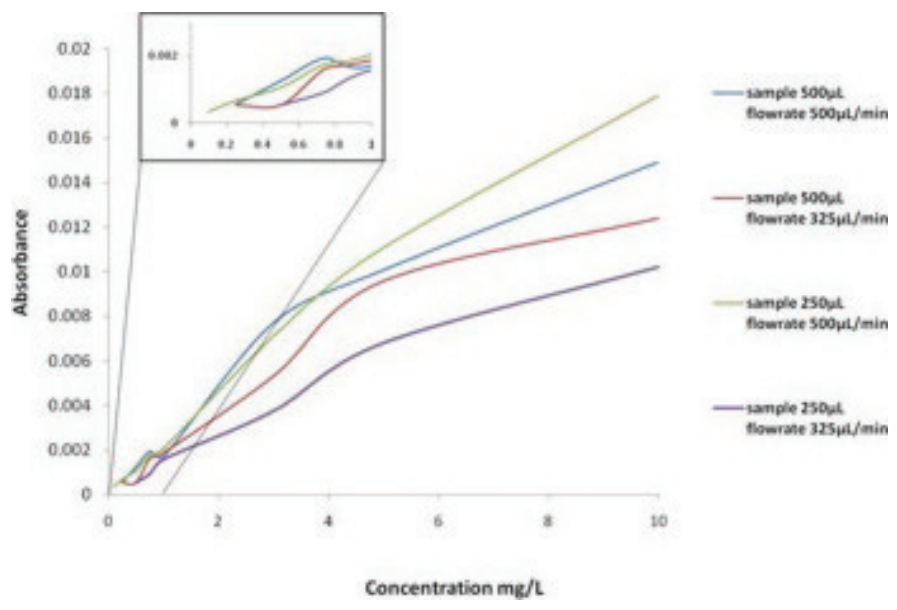

Fig. 5. Plot of absorbance vs. Concentration for different sample-flow rate relationships.

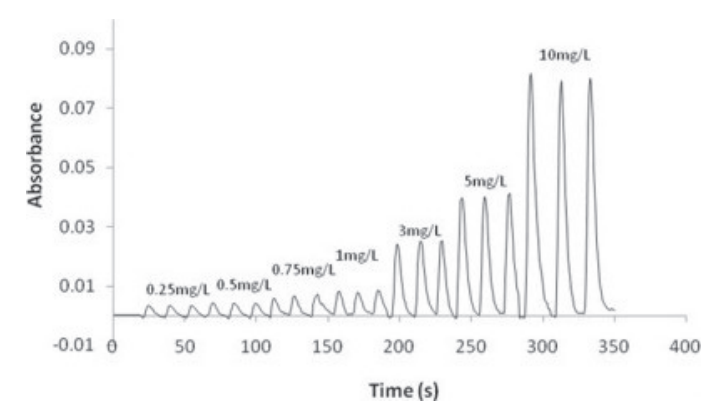

Fig. 6. Absorbance vs. Time.

\section{Conclusions}

The chemical reaction is optimized by omitting a boil of the reactants at $80{ }^{\circ} \mathrm{C}$ and by decreasing the volume of reagents used in the system. The design and construction of a LTCC micro system for the continuous measurement of cobalt in

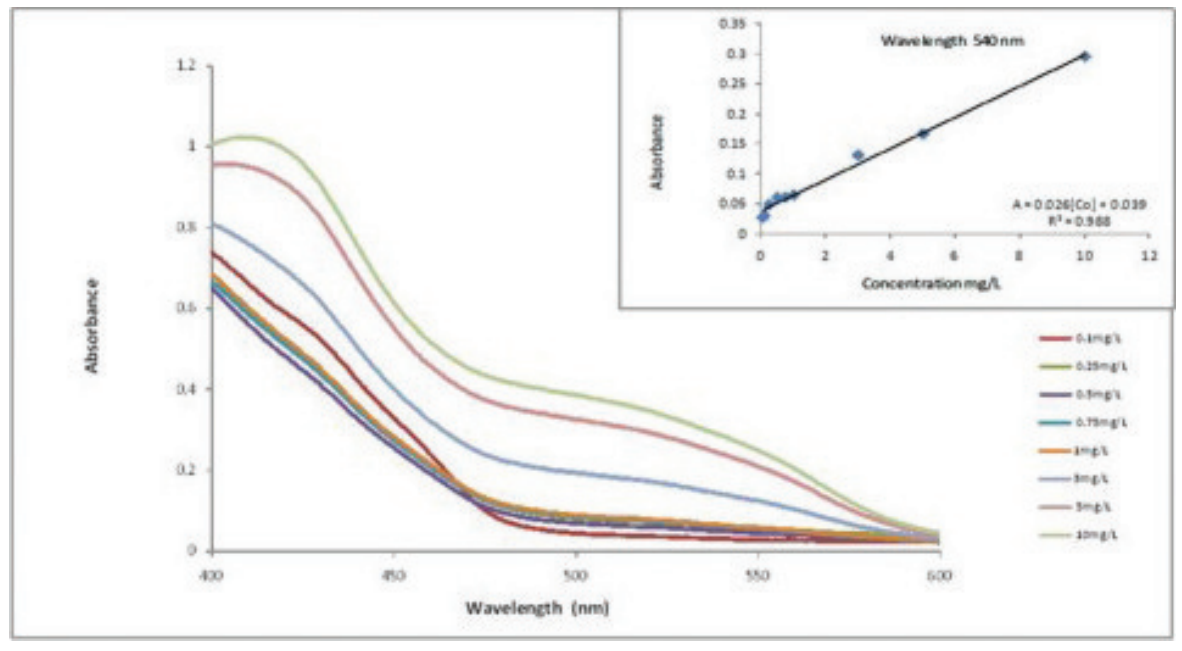

Fig. 4. Absorbance vs. Wavelength wave for different concentrations of cobalt, and correlation $\mathrm{R}^{2}$ at $540 \mathrm{~nm}$. 


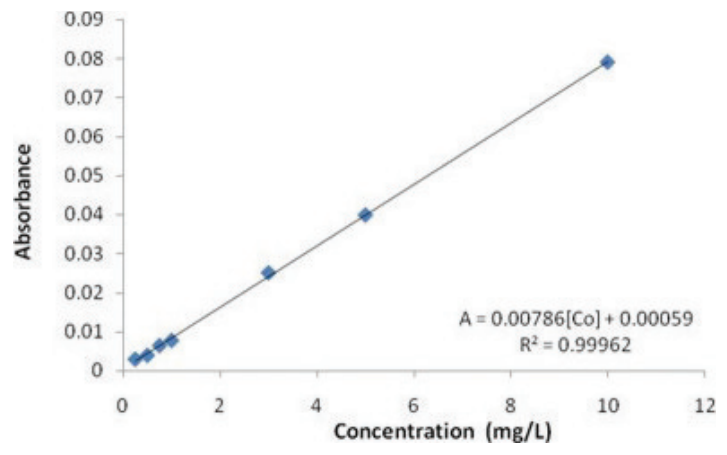

Fig. 7. Equation and $\mathrm{R}^{2}$ of the analytical signal and the different patterns of cobalt.

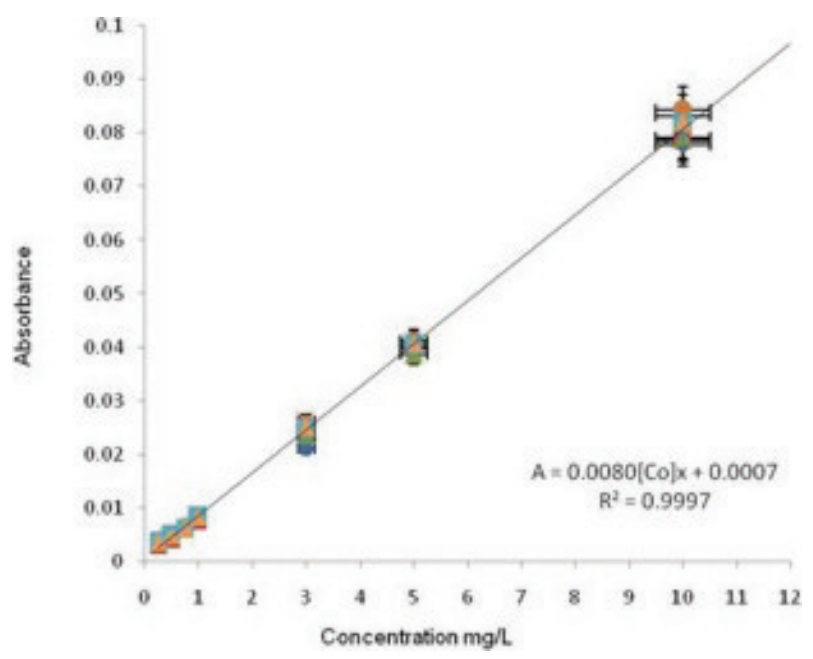

Fig. 8. Linear relationship between concentration and absorbance obtained on a 10 day period.
Table 2. Operating parameters.

\begin{tabular}{lcc}
\hline \multicolumn{3}{c}{ Comparison of analysis method } \\
\hline & Hayashibe et al. & Implemented method \\
\hline Wavelength $(\lambda \mathrm{nm})$ & 520 & 540 \\
Flow Rate $(\mathrm{ml} / \mathrm{min})$ & $1.5-2$ & 0.5 \\
$\begin{array}{l}\text { Response temperature } \\
\left({ }^{\circ} \mathrm{C}\right)\end{array}$ & 80 & 25 \\
lowest concentration & 0.12 & $0.1-0.25$ \\
detected in the system & & \\
$(\mathrm{mg} / \mathrm{L})$ & & \\
\hline
\end{tabular}

aqueous solutions was achieved. The resulting microsystem uses colorimetric detection.

The micro system shows a linear response and a good reproducibility for measurements made in a period of 13 days. The results obtained serve as a basis for real time measurement of cobalt in aqueous solutions in industrial applications.

\section{Acknowledgements}

The authors acknowledge the collaboration of the Sensors and Biosensors Group at the Autonomous University of Barcelona, as well as partial financial aid of Met-Mex Peñoles S.A. de C.V., and the Consejo Nacional de Ciencia y Tecnología of Mexico (CONACYT).

Table 1. Absorbance Tests - concentration in the LTCC team for the colorimetric determination of Co in a 10 day period.

\begin{tabular}{cccccccc}
\hline \multirow{2}{*}{ Day } & \multicolumn{5}{c}{ Average absorbance obtained by triplicate } \\
\cline { 2 - 7 } & 0.25 & 0.5 & 0.75 & 1 & 3 & 5 \\
\hline $\mathbf{1}$ & 0.00301 & 0.00422 & 0.00655 & 0.00803 & 0.02115 & 0.03983 \\
$\mathbf{2}$ & 0.00301 & 0.00426 & 0.00612 & 0.00764 & 0.02479 & 0.04041 & 0.07778 \\
$\mathbf{3}$ & 0.00409 & 0.00537 & 0.00625 & 0.00852 & 0.02372 & 0.03865 \\
$\mathbf{4}$ & 0.00386 & 0.00457 & 0.00640 & 0.00819 & 0.02624 & 0.04131 & 0.07913 \\
$\mathbf{5}$ & 0.00337 & 0.00462 & 0.00631 & 0.00806 & 0.02322 & 0.03963 \\
$\mathbf{6}$ & 0.00377 & 0.00538 & 0.00663 & 0.00885 & 0.02555 & 0.04101 & 0.07858 \\
$\mathbf{7}$ & 0.00355 & 0.00474 & 0.00638 & 0.00823 & 0.02553 & 0.04091 & 0.08208 \\
$\mathbf{8}$ & 0.00367 & 0.00491 & 0.00631 & 0.00827 & 0.02415 & 0.03973 \\
$\mathbf{9}$ & 0.00377 & 0.00495 & 0.00645 & 0.00844 & 0.02532 & 0.04068 \\
$\mathbf{1 0}$ & 0.00356 & 0.00477 & 0.00638 & 0.00824 & 0.02469 & 0.07993 \\
$\mathbf{1 1}$ & 0.00367 & 0.00502 & 0.00644 & 0.00845 & 0.02480 & 0.08244 \\
$\mathbf{1 2}$ & 0.00366 & 0.00490 & 0.00642 & 0.00837 & 0.02521 & 0.04041 & 0.08103 \\
$\mathbf{1 3}$ & 0.00363 & 0.00486 & 0.00637 & 0.00829 & 0.02468 & 0.04026 & 0.08176 \\
Standard deviation & 0.0003071 & 0.0003504 & 0.000126 & 0.0002855 & 0.001296 & 0.0007022 & 0.001954 \\
\hline
\end{tabular}




\section{References}

1. Mawatari, K.; Kazoe, Y.; Aota, A.; Tsukahara, T.; Sato, K.; Kitamori, T. J. Flow Chem. 2012, 1, 3-12.

2. Pons, C.; Miró, M.; Becerra, E.; Estela, J. M.; Cerd, V. Talanta 2004, 62(5), 887-895.

3. Xu, X.; Zhang, S.; Chen, H.; Kong, J. Talanta 2009, 80, 8-18.

4. Golonka, L. J. Sensor Actuat. B-Chem. 2005, 112, 396-402.

5. Harris D.C. Quantitative Chemical Analysis. Eighth ed., W.H. Freeman and Company, New York, 2003.

6. Martínez, C.S.; Ibáñez, N.; Valdés, F.; Alonso, J. Anal. Chem. 2007, 79, 8376-8380.

7. Ibáñez, N.; Bautista, M.; Mendes, Z.; Góngora, M.R.; Alonso, J.; Seabra, C.A. Anal. Chem. 2006, 78 (9), 2985-2992.

8. Pyrzynska, K.; Janiszewska, Z. Analyst 1994, 119,1553-1556.

9. Muñoz, E.; Palmero, S.; García-Garcí, M.A. Talanta 2002, 57(5), 985-992.

10. Ghasemi, J.; Shahabadi, N.; Seraji, H.R. Anal. Chim. Acta 2004, 510, 121-126.

11. Yun, J.; Cho, H. Talanta 2000, 52, 893-902.

12. VanKlooster, H. S. J. Am. Chem. Soc. 1921, 43, 746-749.

13. Dzherayan, T.G.; Shkinev, V.M. Talanta 2002, 57, 7-13.

14. Pournaghi Azar, M.H.; Dastangoo, H. Microchem. J. 2000, 64, 187.

15. Ivanov, V.M.; Mamedova, A.M. J. Anal. Chem., 2006, 61, 571575 .
16. Peterson, K.A.; Knudson, R.T.; Mixdes 2008, 1, 23-37.

17. Gouvea L. R.; Morais, C. A.; Minerals Engineering, 2007, 20 (9), 956-958.

18. Fathi Habashi, Hydrometallurgy, 2006, 79 (1), 15-22.

19. Ibáñez, G.N.; Alonso, J.; Martínez, C. S.; Valdés, F.; TrAC-Trend Anal. Chem, 2008, 27, 24-33.

20. O'Toole, M.; Tong Lau, K. Talanta 2005, 66, 1340-1344.

21. Hayashibe, Y.; Takeya, M. U.S.A. patent, 178,771, 1993.

22. Hayashibe, Y.; Takeya, M.; Sayama, Y. Talanta 1994, 41, 531536.

23. Purachat, B.; Liawruangrath, S. Anal. Sci. 2001, 17, 443-449.

24. Kaur, V.; Kumar Malik, A.; Talanta 2007, 73, 425-430.

25. Da Rocha, M.; Martínez-Cisneros, C.S.; Seabra, A.C.; GóngoraRubio, M.R.; Valdés, F.; Alonso, J. Ibersensor Lisboa, Portugal, 2010.

26. Dittrich, P.S.; Schwille, P. Anal. Chem., 2003, 75 (21), 57675774.

27. González Crevillén, A.; Hervás, M.; López, M.A.; González, M. C.; Escarpa, A. Talanta 2007, 74, 342-357.

28. Thelemann, T.; Thust, H.; Hintz, M. Microelectronics International 2002, 19, 19-23.

29. Golonka Leszek, J.; Zawada, T. Int. J. Appl. Ceram. Tec. 2006, 3 , 150-156.

30. Golonka, L.; Bembnowicz, P. Opt. Appl. 2011, 41 (2).

31. Haji Shabani, A. M.; Dadfarnia, S.; Dehghan, K. Talanta 2003, 59, 719-725. 